\title{
Electrodiagnostic Abnormalities in 15 Patients with Postraumatic Syringomyelia: Pre- and Postoperative Studies
}

\author{
F. M. Dyro, M.D.; ${ }^{1}$ and A. B. Rossier, M.D. ${ }^{2}$ \\ ${ }^{1}$ Assistant Professor of Neurology, Harvard Medical School, Director, Clinical \\ Neurophysiology Laboratory and ${ }^{2}$ Professor of Spinal Cord Rehabilitation, Depart- \\ ment of Orthopaedic Surgery, Harvard Medical School. Chief, Spinal Cord Injury \\ Section, Veterans Administration Medical Center, 1400 VFW Parkway, West \\ Roxbury, Massachusetts 02132, U.S.A.
}

\section{Summary}

$A$ review of 15 patients with posttraumatic syringomyelia indicates that the most reliable electrodiagnostic criteria for the diagnosis of syrinx are the loss of motor unit numbers with increase in motor unit amplitude and duration and synchronous firing. Prolongation of $F$ wave latency in a previously stable patient is a useful observation. Return of function and improvement of $F$ wave latencies can occur rapidly following decompression of the syrinx. Forty per cent of the patients studied had concomitant involvement of at least one peripheral nerve as one would expect invoking the double crush hypothesis.

Key Words: Syringomyelia; Spinal cord injury; Electrophysiology.

Posttraumatic syringomyelia has been reported with an incidence of 0.9 to 1.6 per cent as a long term sequel to spinal cord injury (Williams et al., 1981; Shannon et al., 1981; Rossier et al., 1981). The diagnosis is made clinically on the basis of increasing weakness following a previously stable lesion and a dissociated sensory loss. Electrophysiological criteria for the diagnosis of syrinx include evidence of anterior horn cell loss with presence of a lower motor neuron deficit. DiBenedetto and Rossier (1977) reported that the most common abnormalities were presence of polyphasic increased amplitude action potentials and increased motor unit duration. Increase in synchronisation with two channel recording was felt to be an important sign of anterior horn cell involvement. The difficulty of distinguishing new loss of function from underlying pathology in the cervical region was stressed as a major problem.

We have reviewed all our cases of syringomyelia in patients with traumatic myelopathy. This series includes three patients previously reported by DiBenedetto and Rossier. 


\section{Patient Selection}

Fifteen patients with posttraumatic syringomyelia were studied electrodiagnostically, some serially, during the course of their initial presentation and subsequent treatment. Eight patients were treated surgically after having the diagnosis of syrinx made on computerised axial tomography. Seven patients were diagnosed clinically but did not have surgical intervention. the eight patients undergoing surgical decompression were studied before and after surgery. All of the patients studied were white males from 21-62 years old (Table 1).

Table 1 Patients with Posttraumatic Syringomyelia

\begin{tabular}{|c|c|c|c|c|c|}
\hline Patient & $\begin{array}{l}\text { Age when } \\
\text { studied }\end{array}$ & Date of injury & Bony level & Neuro. Level & $\begin{array}{l}\text { Onset of } \\
\text { symptoms }\end{array}$ \\
\hline \multicolumn{6}{|c|}{ Surgically treated } \\
\hline D.B. & 37 & $8 / 16 / 70$ & $\mathrm{C} 6, \mathrm{C} 7$ & $\begin{array}{l}\text { Incomplete C8 } \\
\text { Complete T2 }\end{array}$ & $\begin{array}{l}\text { November } \\
1975\end{array}$ \\
\hline E.O. & 55 & $12 / 11 / 53$ & C5 & Incomplete $\mathrm{C} 5$ & Fall 1970 \\
\hline S.T. & 52 & $2 / 02 / 73$ & $\mathrm{~T} 2-\mathrm{T} 4$ & Complete T4 & July 1976 \\
\hline A.S. & 26 & $5 / 31 / 68$ & $\mathrm{~T} 12-\mathrm{L} 1$ & Complete T12 & January 1972 \\
\hline D.S. & 34 & $10 / 16 / 68$ & $\mathrm{~T} 11-\mathrm{T} 12$ & $\begin{array}{l}\text { Sensory } \\
\text { incomplete } \\
\text { Motor complete } \mathrm{T} 11\end{array}$ & January 1974 \\
\hline M.S. & 21 & $4 / 20 / 79$ & $\mathrm{C} 3, \mathrm{C} 4, \mathrm{C} 6$ & Complete $\mathrm{C} 7-8$ & January 1981 \\
\hline C.O. & 33 & $9 / 15 / 79$ & C6-C7 & Complete C7 & May 1981 \\
\hline C.C. & 37 & $6 / 03 / 72$ & C6, T4, T5 & Complete C8 & 1979 \\
\hline \multicolumn{6}{|c|}{ Non-operated } \\
\hline J.M. & 53 & $4 / 07 / 50$ & $\mathrm{~T} 11-\mathrm{T} 12$ & $\begin{array}{l}\text { L3-4 complete } \\
\text { with sacral sparing }\end{array}$ & 1970 \\
\hline J.T. & 55 & $1 / 19 / 57$ & $\mathrm{C} 5$ & C6-C7 complete & $\begin{array}{l}\text { February, } \\
1981\end{array}$ \\
\hline W.O. & 60 & $7 / 11 / 75$ & C6 & $\begin{array}{l}\text { C6 ant. cord } \\
\text { syndrome }\end{array}$ & Spring 1978 \\
\hline K.M. & 39 & $8 / 07 / 62$ & T12-L1 & Incomplete $\mathrm{T} 12$ & January 1979 \\
\hline R.S. & 34 & $4 / 04 / 77$ & $\mathrm{C} 6-\mathrm{C} 7$ & $\begin{array}{l}\text { Incomplete } \\
\text { sensory C7 } \\
\text { sensory \& motor }\end{array}$ & July 1979 \\
\hline R.K. & 36 & $6 / 02 / 76$ & $\mathrm{C} 7$ & Complete C8 & April 1979 \\
\hline C.S. & 62 & $11 / 20 / 77$ & None & $\begin{array}{l}\text { C5 ant. cord } \\
\text { (spondylosis) }\end{array}$ & Early 1981 \\
\hline
\end{tabular}

\section{Methods}

Electrodiagnostic studies including sensory and motor conductions in median, ulnar and at times radial nerves were measured. TECA Model TE 4 electromyograph (TECA Corp., Pleasantville, NY) with built in stimulator was used. Electromyography was performed using monopolar needle electrodes in most cases. In some patients somatosensory evoked potentials were measured on stimulation of the median or ulnar nerve at the wrist with recording from contralateral cortical electrodes. F wave latency was determined by recording $10 \mathrm{~F}$ wave responses and measuring the latency to the response of earliest onset using the method of Magladery (1950). When atrophy of the hand intrinsics made recording from the abductor pollicis brevis and abductor digiti minimi impossible, recordings were made from the wrist flexors or extensors. There were two 
control groups matched for age and sex. One group of asymptomatic able bodied patients and a second group of otherwise asymptomatic spinal cord injured men.

\section{Case reports}

Eight patients were studied before and after decompression of syringomyelia. The cases are reported in detail below. In most cases there was improvement electrically in the number of motor units during voluntary contraction and a reduction of positive sharp waves and fibrillations following decompression.

1. D.B. is a 37-year-old man who sustained C6 and C7 fractures in a diving accident in 1970, incurring an incomplete C8, complete T2 tetraplegia. In November 1975 he developed weakness in the C8 hand muscles (left) as well as loss of temperature in the right arm. He had neck pain radiating into both upper extremities. EMG on 29 December 1975 suggested bilateral C5/6 and C8 radiculopathy. By 4 March 1976 his sensory level had ascended to C2/3 (patient supine) and EMG showed anterior horn cell involvement including fibrillations, positive waves, fasciculations, and increased amplitude motor units. There was 95 per cent synchronization in deltoids and biceps. Surgery was performed on 30 June 1976. Followup on 26 April 1976 showed complete denervation of the left first dorsal interosseus muscle and decreased recruitment on the right, but the number of polyphasic units and previously seen abnormalities of motor unit amplitude and duration in other muscles had improved. On 8 April 1980 the patient was retested because of decreasing function in the right hand. He was found to have good function in the biceps, deltoid, trapezius, triceps bilaterally with only slight decrease in recruitment in triceps and wrist extensors. There was at this time an ulnar conduction block at the right cubital tunnel and a right carpal tunnel syndrome. The patient underwent decompression of the right median and ulnar nerves. Left C8-T1 function was not regained. SSEP's were prolonged and distorted.

2. E.O. is a 57-year-old man who sustained a C5 fracture in 1953 with incomplete motor and sensory myelopathy. In 1970 he first experienced transient shoulder pain. In 1972 he began to develop increased arm and leg weakness and an ice-pack pressure feeling in the back, neck and head. EMG showed increase in motor unit potential duration, increased amplitude units and up to 50 per cent polyphasic units especially in C5 distribution. A C3-6 syrinx was decompressed on 8 June 1976 . When rested on 16 June 1976 this man had normal conduction velocities in the median nerves. There was some loss of right biceps and deltoid function with the presence of increased amplitude polyphasic motor units representing residual $\mathrm{C} 5-6$ root damage.

3. S.T. is a 52-year-old man who sustained fractures of T2-T3 and T4 in February 1973. He also dislocated his left shoulder at the same time. Six months postinjury he had pain in the dorsal spine and both arms. In 1976 he developed pain at $\mathrm{C} 4$ radiating into both arms with numbness in the left hand and face and pain in the right upper extremity. Sensory examination revealed deficits at $\mathrm{C} 3$ and $\mathrm{C} 4$ as well as in left trigeminal distribution. Air myelogram showed dilatation of the cord from C3 to T1 suggestive of syrinx. This was decompressed on 14 June 1976. Motor and sensory conduction velocities preoperatively were normal except for delayed conduction along the left ulnar nerve in the cubital 
tunnel. Electromyography showed decreased motor units in the right biceps and triceps. Fibrillations and fasciculations were recorded as well as synchronization of firing on maximal effort. 25 January 1978 the patient was restudied because of decreased left handgrip strength. Ulnar conduction was found to be slow. When restudied in 1980 the conduction velocities on the right were normal but left median and ulnar distal sensory and motor latencies were very abnormal and conduction velocities were slow (median $39.6 \mathrm{~m} / \mathrm{sec}$; ulnar $32.2 \mathrm{~m} / \mathrm{sec}$ ).

4. A.S. is a 33-year-old man who sustained a T12-L1 fracture dislocation in 1968. In 1972 he began to complain first of numbness in the left upper extremity which was followed by shoulder pain. Sensory level eventually ascended to C2 on the left and $\mathrm{C} 4$ on the right. He reported that he had fallen on his left shoulder and when tested had weakness of the thumb abductor and the deltoid. Left median distal motor latency was markedly prolonged at $13.2 \mathrm{msec}$. The median sensory response was absent bilaterally. The patient was felt to have bilateral carpal tunnel syndrome. The left wrist was decompressed. In 1977 EMG was carried out because the patient had increased left deltoid weakness. There was slowing of axillary nerve conduction with a latency to the anterior deltoid of $8 \mathrm{msec}$. There was synchronization of firing of motor units in the deltoid with polyphasic increased amplitude potentials in rhomboids as well (C5). A syrinx was decompressed on 16 February 1977 . Studies repeated over the next several months showed improvement in deltoid function with return of axillary nerve latency to normal. On 14 March 1979 a repeat EMG was done because of right hand weakness. This turned out to be a right median nerve entrapment at the carpal tunnel. The left deltoid remained at about 80 per cent of full interference pattern. The patient developed a left shoulder Charcot joint.

5. D.S. is a 34-year-old heavyweight lifting champion. He sustained a T11T12 fracture dislocation on 16 October 1968. In 1974 after sneezing he noticed numbness in the left hemithorax and neck, followed 5 years later by weakness of the left upper extremity without muscle wasting. Conduction velocities, evoked responses amplitudes and distal sensory and motor latencies were normal. EMG showed chronic motor unit loss with some 10-15 mV 'giant units' in C4, 5, 6 distribution. Only 1-2 motor units were present at needle tip in upper trapezius. Interference pattern was 50 per cent of normal in sternocleidomastoid and in rhomboids. Hand intrinsics and wrist flexors and extensors were normal. F wave latencies were abnormal pre-operatively. On 20 September 1979 a C5 laminectomy was performed and a $3 \mathrm{~cm}$ long $\mathrm{T}$ tube was inserted in the syrinx. Followup on 9 May 1980 and 14 August 1980 and 22 September 1981 showed marked improvement in motor unit numbers, decrease in polyphasicity and amplitude and improvement in $\mathrm{F}$ wave latencies.

6. M.S. is a 21-year-old man who sustained a complete tetraplegia C7 following fractures of C3, C4 and C6 on 20 April 1979. In late 1980 he experienced pain in the right shoulder followed by increased weakness of the wrist extensors. Latencies to flexor carpiradialis (FCR) stimulating the median nerve in the anticubital fossa were normal at $2.6 \mathrm{msec}$ bilaterally. Radial conduction from spiral groove to antecubital fossa was $73.7 \mathrm{~m} / \mathrm{sec}$ on the right and $60 \mathrm{~m} / \mathrm{sec}$ on the left. Normal sensory latencies were obtained from all fingers except the right little finger. F wave latencies to FCR were prolonged on 34.3 on the right with frequent blocking. Motor units in biceps and deltoid were of $8-10 \mathrm{mV}$. In FCR 
and extensor carpiradialis (ECR) some polyphasic 4-6 mV units were seen. Only 1-2 motor units responded in ECR. Pectoralis and triceps were the same as FCR. Polyphasic units and decreased numbers were found in deltoid and upper trapezius on the left. There was complete lower motor neuron denervation of the hand muscles.

A syrinx was drained at C4 on 23 January 1981. A postoperative study was carried out on 15 April 1981. Conduction in the median nerve recorded from FCR was normal at $71.4 \mathrm{~m} / \mathrm{sec}$ on right and $60 \mathrm{~m} / \mathrm{sec}$ on left. F wave latencies to FCR were improved at $25.4 \mathrm{~m} / \mathrm{sec}$ on right and slightly longer at $27 \mathrm{~m} / \mathrm{sec}$ on left. F wave responses were of low amplitude and not seen consistently. EMG showed increase in motor unit numbers in all but the hand muscles. Followup on 26 February 1982 showed right $\mathrm{F}$ wave latency to FCR of $24.3 \mathrm{~m} / \mathrm{sec}$ and evidence of early of innervation in hand muscles. There was a significant increase in C5-6 musculature interference patterns with up to 90 per cent of full pattern in biceps, rhomboids and supraspinatus. Motor unit amplitudes were 4-6 $\mathrm{mV}$.

7. C.O. is a 33-year-old man who experienced a complete C7 tetraplegia following fracture of $\mathrm{C} 7$ and anterior dislocation of $\mathrm{C} 6$ and $\mathrm{C} 7$ in an automobile accident on 15. September 1979. He had a posterior fusion of C5 to C7 18 hours post injury. Twenty-months post injury he developed left subscapular pain. This increased and by 23 months post injury he had a suspended sensory level at C3-C6 on the left. EMG revealed a decrease in motor unit numbers in rhomboid, supraspinatus, trapezius and sternocleidomastoid. Somatosensory evoked potentials from the arms were normal. Computerised tomography and air myelography were suggestive of a cavitation at C6 which was drained on 24 September 1981. A followup studied in November 1983 showed moderate increase in motor unit numbers in C5-6 distribution although the patient noticed no change in total strength.

8. C.C. is a 37-year-old man who sustained C6 and T4 fractures on 3 June 1972. He developed burning pain in the left shoulder 7 years post injury. EMG on October 1981 showed mild to moderate loss of motor units in C5, C6 distribution with fatiguing, synchronous firing and high amplitude polyphasic motor units. Sensory potentials were normal. On 19 November 1981 he underwent drainage of a cyst at the C5 cord level. Followup EMG on 19 January 1982 showed a left ulnar entrapment at the wrist but much improved EMG and shortening of $F$ wave latencies which had been prolonged. Another study on 31 January 1983 showed continued improvement in function especially in hand muscles. $F$ waves which could not be measured in hand intrinsics initially were normal on the right and prolonged but present on the left.

\section{Patients not treated surgically}

9. J.M. is a 53-year-old man who sustained a T11-T12 fracture dislocation in an automobile accident on 7 April 1950. Twenty years post injury he first noticed numbness on the right side of the head followed by pain in the right shoulder. Nine years later he noticed weakness in the right hand. In 1980 there was a suspended dissociated sensory deficit from C2-T2 on the right with analgesiaanaesthesia at L3 bilaterally. EMG on 14 March 1980 suggested a C8-T1 root involvement and the right ulnar $\mathrm{F}$ wave was prolonged. Left median sensory 
latency was borderline at $3.4 \mathrm{msec}$. On 3 June 1980 a repeat study showed denervation in C6 distribution but no fasciculations. No synchronous firing was recorded. SSEP's on median stimulation were normal at 16.4 on right and 16.7 on left.

10. J.T. is a 55-year-old man who sustained a complete C6 tetraplegia following a C5 fracture on 19 January 1957. In 1980 he experienced bilateral chest pain with shortness of breath and abdominal and groin pain. When tested on 6 May 1981 his sensory level had ascended to C2 bilaterally. On electrophysiological study he had very low amplitude responses from the hand muscles but normal conduction velocities. There was significant motor unit loss in biceps, triceps, deltoid and mentalis. Trapezius and sternocleidomastoid were normal. One month later because of deteriorating pulmonary function phrenic nerve stimulation was done. Responses were of very low amplitude bilaterally. F wave latencies were prolonged. CT scan on 13 May 1981 showed a cavity at C2-C6.

11. W.O. a 60-year-old man sustained an incomplete C6 tetraplegia following an auto accident on 11 July 1975 without evidence of cervical fracture. In the Spring of 1978 he noted increased numbness in the feet as well as pain in the neck. In 1979 he experienced hyperpathia below C4 bilaterally. When tested on 18 September 1979 he was found to have a tardy ulnar palsy, C5/6 root involvement and anterior horn cell loss at C8/T1. Subsequent testing on 31 January 1980, 5 June 1980, 5 June 1981 have shown continued ulnar slowing on the left with prolongation of left ulnar F wave latency and chronic C6-7, C8/T1 changes. CT scan on 10 June 1981 showed possible contrast material inside the spinal cord at C5-C6.

12. K.M. is a 39-year-old man who sustained a T12-L1 fracture dislocation on 7 August 1962 leaving him with an incomplete T12 paraplegia. Since January 1979, he complained of aching and numbness in both arms without neck pain. CT scan with metrizamide on 15 October 1981 was suggestive of cyst formation at the C4 level. Air myelogram on 6 January 1982 revealed an enlarged cord at the C5/6 level. He was not aware of weakness. Electrodiagnostic testing revealed the latency to the deltoids to be normal at $4.0 \mathrm{msec}$ bilaterally. Needle electromyography showed fasciculations and fibrillations in deltoid, biceps, supraspinatus infraspinatus and brachioradialis on the left. Interference pattern was 90 per cent of normal. There were increased amplitude motor units and atendency to synchronisation. $\mathrm{F}$ wave latencies were within normal limits.

13. R.S., a 34-year-old man sustained fractures of $\mathrm{C} 6$ and $\mathrm{C} 7$ with posterior dislocation of $\mathrm{C} 6$ and $\mathrm{C} 7$ in an airplane accident on 4 April 1977. In addition he had bilateral clavicular fractures and a dislocated left shoulder. His functional level was $\mathrm{C} 7$ sensory incomplete and $\mathrm{T} 1$ motor and sensory complete. In July 1979 he complained of throbbing left earache and left flank pain. A dissociated sensory level to $\mathrm{C} 2 / 3$ on the left was found. EMG was positive for $\mathrm{C} 5$ involvement. On 13 October 1981 a CT scan with metrizamide showed enlargement of the cervical cord at its upper part without evidence of cystic degeneration.

14. R.K. is a 36-year-old man who fell from scaffolding sustaining a fracture of C7 with complete tetraplegia of C8 bilaterally. Three years after injury his appreciation of pinprick was decreased at C6/7 bilaterally and by 1981 had ascended to $\mathrm{C} 5 / 6$. He was having increased weakness in the hand intrinsics. EMG showed prolonged $\mathrm{F}$ wave latencies and decreased numbers of high amplitude 
units primarily in C5 distribution. CT scan with metrizamide on 1 December 1981 showed several high density zones at the $\mathrm{C} 1$ level suggesting intramedullary cavitation.

15. C.S. This 62-year-old man sustained a C5 incomplete anterior cord syndrome on 20 November 1977. In 1981 he began to have increased stiffness in his arms and sensory changes in his lower extremities. EMG and nerve conduction studies showed peripheral neuropathy in the legs but evidence of motor neuron involvement at the $\mathrm{C} 5$ level on the left with decreased motor unit numbers, high amplitude units and synchrony of firing. Followup on $26 \mathrm{March}$ 1982 showed increased prolongation of $\mathrm{F}$ wave latencies, continued loss of $\mathrm{C} 4$, 5, 6 motor unit numbers and ascending sensory level.

\section{Results}

Of fifteen patients studied only six had their original site of injury in the thoracic region. Nine had injuries in the cervical region ( $\mathrm{C} 5-\mathrm{C} 8$ root levels). In all cases new weakness and sensory deficit were superimposed upon pre-existing deficits. Interval between the injury and onset of symptoms suggestive of syrinx was from 1-24 years. Average 8 years. Eight patients were studied pre and postoperatively. Five of these patients had co-existing injuries in the cervical region, three had thoracic levels. Improvement based upon evidence of return of motor unit function, loss of fibrillation potentials and restoration of motor units of normal appearance was seen to some extent in all patients decompressed. Most striking improvement was seen in DS who was decompressed within weeks of onset of new symptoms and in AS decompressed within 18 months. Pre-operatively there was evidence of anterior horn cell loss at two or more levels most commonly C5, C6 unlike patients studed by Schwartz et al. (1980). Some fasciculations and fibrillations were seen especially in the more acute lesions. Absence of fibrillations was not unusual in the lesions of longstanding indicating slow progression. Decrease in the interference pattern and a gradual increase in motor unit amplitude and duration was seen before the patient was aware of any motor deficit. Synchronization was commonly seen as a concomitant of anterior horn cell loss. Slowing of nerve conduction without peripheral entrapment was also seen as a function of anterior horn cell loss. In three patients $F$ wave latencies measured pre and postoperatively were seen to improve (Table 2). Giant motor units are motor unit potentials of more than $10 \mathrm{mV}$. These are a result of axonal loss with reinnervation by remaining axon producing an enlarged motor unit territory, thus a higher amplitude electrical response. Synchronisation is a manifestation of the same phenomenon and is best seen with two electromyographic electrodes in different section of the same muscle belly.

Table 2 F-wave latencies (shortest latency response of 10 responses measured)

\begin{tabular}{lcc}
\hline & Median & Ulnar \\
\hline Normal controls & $27 \cdot 1 \pm 1.4 \mathrm{msec}$ & $27.9 \pm 1.2 \mathrm{msec}$ \\
Spinal cord injured patients without suspected & $27 \pm 2.5 \mathrm{msec}$ & $27.5 \pm 2 \mathrm{msec}$ \\
syringomyelia & $31.1 \pm 2.9 \mathrm{msec}$ & $30.1 \pm 1.6 \mathrm{msec}$ \\
Patients with documented syrinx & \\
\hline
\end{tabular}




\section{Discussion}

In disorders of anterior horn cells or in trauma to AHC it has long been believed that overall slowing occurs because of preferential loss of larger, faster conducting fibres (Jusic and Milic, 1972; Carleton and Brown, 1979; Krasilovsky, 1980).

The F response first described by Magladery and McDougal (1950) is believed to represent centrifugal discharges from individual motor neurons initiated by antidromic volleys along their axons. The afferent and efferent arcs of the $F$ response consist of the same alpha motor axons.

$\mathrm{F}$ waves are usually diphasic potentials occurring at some time after the $M$ or motor response and elicited by applying a stimulus 25 per cent above supramaximal stimulus needed to produce an $M$ wave. Latency, form and amplitude of the $\mathrm{F}$ wave vary depending upon the available pool of responding axons and the size of motor unit territories. In anterior horn cell disease the $F$ wave is prolonged in latency. The $\mathrm{F}$ wave of shortest latency is that conducted by the fastest surviving motor fibres, which in the case of ALS are not the largest and fastest possible. Amplitude is increased because of collateral reinervation of surviving motor units (Argyropoulos et al., 1978). A reversible situation exists in conduction block due to cervical rib and band. Wulff and Gilliatt (1979) have shown improvement in $\mathrm{F}$ wave latency in one patient out of five following decompression of cervical rib and band. This was felt to be due to restored conduction of a few large motor axons which had been previously blocked.

In our patients the recovery of $F$ wave response and the rather rapid recovery of motor unit function cannot be due to reinnervation by sprouting and cannot be due to formation of new anterior horn cells. It is postulated that during the acute expansion of a syrinx, anterior horn cells are affected adversely but reversibly by edema and local increases in pressure due to the expanding mass. These 'sick' motoneurones are then not capable of responding to antidromic volleys. When the syrinx is decompressed these sick motoneurones recover from their malaise and are able to respond again to antidromic volleys, as well as to reestablish their neural supply to muscle fibres in their motor unit pool (McComas et al., 1975) and Rydevik and Nordborg (1980) have suggested that this type of malaise and return of function may be possible. Normal $F$ wave latencies from flexor carpi radialis are $19.4 \pm 1.6 \mathrm{~m} / \mathrm{sec}$.

$\mathrm{F}$ waves are known to be affected by peripheral entrapments. In our patients with $F$ wave prolongation and some evidence of entrapment $F$ waves improved after cyst decompression without peripheral decompression.

\section{Sensory responses}

Typically the sensory potential is preserved in the face of lost sensation and a decrease of the amplitude of the motor response (Fincham and Cape, 1968). Sensory impairment in syringomyelia is dependent on anatomic disruption of sensory tracts and root fibres proximal to the dorsal root ganglion. Because the dorsal root ganglia which contain the cell bodies for the sensory nerves are located outside the cord either within or near intervertebral foramina, spinal roots avulsed from the cord motor axons are disconnected from their anterior horn cells but sensory axons avulsed are preganglionic. The same situation exists in syrinx. 
The central connection from dorsal root to ascending pathway is no longer functioning but the end organ and its cell body still function normally. The exception to this was in our patients with peripheral entrapment, plexus or peripheral neuropathy. Absence or decreased amplitude of the sensory response was seen in all patients with carpal tunnel syndrome or tardy ulnar palsy commented upon in the next section.

\section{Peripheral entrapments}

Six patients of the 15 studied had evidence of peripheral entrapments. Two of these patients had had previous trauma to the left shoulder on the most involved side. These were ST and AS. The results summarised in Table 3. Three patients had abnormal prolongation of median and ulnar distal motor latencies on one side. One had an ulnar entrapment at the cubital tunnel and one (AS) had left axillary nerve slowing in addition to bilateral carpal tunnel syndrome.

Table 3 Peripheral entrapments

\begin{tabular}{|c|c|c|c|c|c|c|c|c|c|c|}
\hline & \multicolumn{4}{|c|}{ Median nerve } & \multicolumn{4}{|c|}{ Ulnar nerve } & \multirow{2}{*}{\multicolumn{2}{|c|}{$\begin{array}{l}\text { Sensory } \\
\text { nl } 3.0 \\
\text { msec }\end{array}$}} \\
\hline & \multicolumn{2}{|c|}{$\begin{array}{l}\text { Distal Motor Latency } \\
\text { Normal }<4.5 \mathrm{msec}\end{array}$} & $\begin{array}{l}\text { Sensory } \\
\text { Normal }\end{array}$ & $\begin{array}{l}\text { Latency } \\
<3.0 \mathrm{msec}\end{array}$ & \multicolumn{2}{|c|}{$\begin{array}{c}\text { Conduction in } \\
\text { Cubital Tunnel } \\
\text { Normal }>42 \mathrm{~m} / \mathrm{sec}\end{array}$} & \multicolumn{2}{|c|}{$\begin{array}{l}\text { Elbow to } \\
\text { Wrist } \\
>48 \mathrm{~m} / \mathrm{sec}\end{array}$} & & \\
\hline & $\mathbf{R}$ & $\mathrm{L}$ & $\mathrm{R}$ & $\mathrm{L}$ & $\mathrm{R}$ & $\mathrm{L}$ & $\mathbf{R}$ & $\mathrm{L}$ & $\mathbf{R}$ & $\mathrm{L}$ \\
\hline A.S. & $4 \cdot 6$ & $13 \cdot 2$ & $4 \cdot 1$ & Absent & & 60 & & 60 & $2 \cdot 1$ & $2 \cdot 1$ \\
\hline W.O. & $3 \cdot 7$ & $3 \cdot 8$ & $2 \cdot 9$ & $3 \cdot 0$ & $58 \cdot 6$ & 34 & & 50 & $2 \cdot 5$ & $3 \cdot 4$ \\
\hline D.B. & $5 \cdot 4$ & & $3 \cdot 0$ & & $17 \cdot 5$ & & 42 & & None & \\
\hline S.T. & $3 \cdot 8$ & $6 \cdot 3$ & $3 \cdot 2$ & $4 \cdot 1$ & & & $59 \cdot 6$ & $32 \cdot 2$ & $2 \cdot 5$ & None \\
\hline C.C. & $4 \cdot 8$ & $5 \cdot 0$ & $3 \cdot 0$ & $3 \cdot 0$ & $44 \cdot 8$ & $71 \cdot 4$ & $59 \cdot 1$ & $34 \cdot 7$ & $2 \cdot 9$ & $3 \cdot 4$ \\
\hline J.M. & $3 \cdot 8$ & $3 \cdot 3$ & $3 \cdot 0$ & 3.0 & $16 \cdot 7$ & $29 \cdot 4$ & $51 \cdot 2$ & $54 \cdot 3$ & None & $2 \cdot 6$ \\
\hline
\end{tabular}

In spite of their concurrent appearance with the formation of the syrinx, drainage of the syrinx did not alter peripheral slowing and decompression of the peripheral nerve was required. An exception to this is the improvement in the axillary latency in patient AS.

This sort of peripheral involvement was previously commented upon by DiBenedetto and Rossier in one patient and has been observed in seven out of 16 patients by Glatzel and Grunes (1976) and in 10 of 28 patients with congenital syrinx reported by Jacobi and Krott (1975). While microtrauma and neurogenic arthropathies are thought to be the cause, another hypothesis is the double crush theory of Upton and McComas (1973). The presence of peripheral slowing and or evidence of actual peripheral entrapment in the face of more proximal lesions has been reported by Upton and McComas and more recently by Dyro, 1983. The coexistence of poor axonal function due to disrupted axoplasmic flow and loss of more vulnerable faster conducting alpha motoneurones probably account for observed abnormalities. In addition quadriparetic and paraplegic people who rely heavily on wheelchairs for mobility do indeed subject the median and ulnar nerves at the wrist and elbow to chronic trauma. Independent peripheral injury at the time of initial trauma must be ruled out (Guyon and Honet, 1977). The presence of underlying root injury, peripheral entrapment and coexistence of a syrinx can create a real diagnostic dilemma. 


\section{Résumé}

Une revue de quinze malades qui souffraient de syringomyélie posttraumatique indique que les critères électrodiagnostiques les plus fiables pour la diagnose du syrinx sont la perte de nombres de l'unité motrice avec l'augmentation de l'amplitude et de la durée de l'unité motrice ainsi que de l'allumage synchrone. La prolongation de la latence d'onde $\mathrm{F}$ chez un malade antérieurement stable est une observation utile. Le retour de la fonction et l'amélioration des latences d'onde $F$ peuvent se produire rapidement suivant la décompression du syrinx. Quarante pour cent des malades étudiés avaient une implication concomitante d'au moins un nerf périphérique comme on pourrait s'y attendre en invoquant l'hypothèse d'écrasement double.

\section{Zusammenfassung}

Eine Übersicht über fünfzehn Patienten mit posttraumatischer Syringomyelie zeigt, dass die zuverlässigsten elektrodiagnostischen Kriterien für die Diagnose der Syrinx sind der Verlust der Motoreinheitzahlen mit Steigung der Motoreinheitamplitude und-dauer und der synchronistischen Anzündung. Verlängerung der F-Wellenlatenz bei einem früher stabilen Patient ist eine nutzvolle Beobachtung. Rückkehr von Funktion und Verbesserung von F-Wellenlatenzen können zufolge der Syrinxentlastung schnell vorkommen. Vierzig prozent der studierten Patienten hatten begleitendes Ergriffensein von mindestens einem peripherischen Nerv, wie zu erwarten wäre, wenn man die Doppelquetschenhypothese anrufen sollte.

\section{References}

Argyropoulos CJ, Panayiotopoulos CP, Scarpalezos S 1978 F- and M-wave conduction velocity in amyotrophic lateral sclerosis. Muscle and Nerve 1:479-485.

CARLTON SA, BROWN WF 1979 Changes in motor unit population in motor neurone disease. Journal of Neurology, Neurosurgery and Psychiatry 42:42-51.

DiBenedetto M, Rossier AB 1977 Electrodiagnosis in posttraumatic syringomyelia. Paraplegia 14:286-295.

DYRo FM 1983 Peripheral entrapments following brachial plexus injuries. EMG and Clinical Neurophys 23/4:251-257.

FinCHAM RW, CAPE CA 1968 Sensory nerve conduction in syringomyelia. Neurology 18:200-201.

GlatZEL W, GRÜNES J-V 1976 Results of electromyographical and electroneurographical investigations concerning syringomyelia. European Neurology 14:60-67.

GUYON MA, HONET JC 1977 Carpal tunnel syndrome or trigger finger associated with neck injury in automobiles accidents. Archives of Physical Medicine and Rehabilitation 58:325-327.

JACOBI HM, KROTT HM 1975 Ulnarisparesen bei syringomyelie. Nerven arzt 46:68-72.

Jusic A, MILIC S 1972 Nerve potentials and afferent conduction velocities in the differential diagnosis of amyotrophy of the hand. Journal of Neurology, Neurosurgery, Psychiatry 35:861-864.

KRASILOVSKY G 1980 Nerve conduction studies in patients with cervical spinal cord injuries. Archives of Physical Medicine and Rehabilitation 61:204-409.

MAGLADERY JW, MCDougal DB 1950 Electrophysiological studies of nerve and reflex activity in normal man. I. Identification of certain reflexes in the electromyogram and the conduction velocity of peripheral nerve fibres. Bulletin Johns Hopkins Hospital 86:265-290.

McComAS AJ, UPTON ARM, JoRGENSEN PB 1975 Recent advances in myology, 1st ed., p 84-90. Excerpta Medica, Amsterdam.

Rossier AB, Foo D, Shillito J, Naheedy MH, Sweet WH, Dyro F, Sarkarati M 1981 Progressive late posttraumatic syringomyelia. Paraplegia 19:96-97.

RYDEviK B, NoRDBERG C 1980 Changes in nerve function and nerve fiber structure induced by acute graded compression. Journal of Neurology, Neurosurgery, Psychiatry 43:1070.

Schwartz MS, Stalberg E, Swash M 1980 Pattern of segmental motor involvement in syringomyelia: a single fiber EMG study. Journal of Neurology, Neurosurgery, Psychiatry 43:150-155.

Shannon N, Symon L, Logue V, Cull D, Kang J, Kendall B 1981 Clinical features, investigation and treatment of post-traumatic syringomyelia. Journal of Neurology, Neurosurgery, Psychiatry 44:35-42.

Upton ARM, MCComas AJ 1973 The double crush in nerve entrapment syndromes. The Lancet p 359, 18 August 1973.

Williams B, Terry AF, Jones HWF, MCSweEney T 1981 Syringomyelia as a sequel to traumatic. Paraplegia 19:67-80.

WulfF CH, GilliatT RW $1979 \mathrm{~F}$ waves in patients with hand wasting caused by cervical rib and band. Muscle and Nerve 2:452-457. 